\title{
Artículo
}

\section{La competencia mediática en los criterios de evaluación del currículo de Educación Primaria}

\author{
Antonia Ramírez García ${ }^{\mathrm{a}}$, Paula Renés Arellano ${ }^{\mathrm{b}, *}$ e Ignacio Aguaded $^{\mathrm{c}}$ \\ a Área de Métodos de Investigación y Diagnóstico en Educación, Facultad de Ciencias de la Educación, Córdoba, España \\ b Área de Teoría e Historia de la Educación, Facultad de Educación, Universidad de Cantabria, Santander, España \\ c Área de Didáctica y Organización Escolar, Facultad de Ciencias de la Educación, Universidad de Huelva, Huelva, España
}

\section{INFORMACIÓN DEL ARTÍCULO}

\section{Historia del artículo:}

Recibido el 27 de mayo de 2015

Aceptado el 31 de agosto de 2015

On-line el 1 de noviembre de 2015

\section{Palabras clave:}

Competencia mediática

Medios de comunicación

Evaluación

Currículo

Educación Primaria

\begin{abstract}
R E S U M E N
El imparable desarrollo de las tecnologías de la información y la comunicación, así como la presencia de los medios de comunicación en nuestra sociedad y las nuevas políticas educativas son factores que han convertido el término de la competencia mediática en foco de interés de investigaciones. Teniendo en consideración las 6 dimensiones de dicha competencia y sus correspondientes descriptores, en este trabajo se ha realizado una revisión de la normativa actual en todas las comunidades autónomas del currículo de Educación Primaria en España con el objetivo de cuantificar la presencia o ausencia de la competencia mediática en el cuarto curso de la etapa de Educación Primaria. La metodología seguida ha sido cualitativa y se ha basado en el análisis de contenido. Los resultados obtenidos muestran la presencia de la competencia mediática en los criterios de evaluación de las diferentes áreas del currículo. Finalmente, se hace una propuesta en la que se relacionan los descriptores de la competencia mediática con los criterios de evaluación del currículo de cuarto de Educación Primaria, destacando que todas las dimensiones de la competencia mediática quedan reflejadas en dichos criterios.
\end{abstract}

(C) 2015 Instituto de Ciencias de la Educación de la Universidad de Oviedo. Publicado por Elsevier España, S.L.U. Este es un artículo Open Access bajo la CC BY-NC-ND licencia (http://creativecommons. org/licencias/by-nc-nd/4.0/).

\section{The presence of media literacy in Primary education curriculum assessment criteria}

\section{A B S T R A C T}

The development of information and communication technology, the presence of the mass media in our society, as well as new educational policies are factors that have made the media literacy a focus of research. There are 6 dimensions of the media literacy along with their indicators. A review is presented on the current legislation in all regions of Spain on the Primary Education curriculum in order to quantify the presence or absence of media competence in the fourth year of Primary Education. The methodology was qualitative and was based on content analysis. The results show the presence of media competence in the assessment criteria of the different areas of the curriculum. Finally, a proposal is made on associating the descriptors of media competence with the assessment criteria in the curriculum of fourth year of Primary Education.

(C) 2015 Instituto de Ciencias de la Educación de la Universidad de Oviedo. Published by Elsevier España, S.L.U. This is an open access article under the CC BY-NC-ND license (http://creativecommons. org/licenses/by-nc-nd/4.0/).

\footnotetext{
* Autor para correspondencia: Universidad de Cantabria, despacho 302. Avda. de los Castros, s/n. 39005 Santander, Tel.: +0034942 2012 72; fax: +0034942 201173 .

Correo electrónico: renesp@unican.es (P. Renés Arellano).
}

\section{Introducción}

Aunque el término competencia se introdujo en nuestro sistema educativo de la mano de la formación profesional, la generalización de este término en él ha tenido lugar hace pocos años, fruto de la publicación de la Ley Orgánica 2/2006, de 3 de mayo, de Educación 
(LOE, 2006). En la actualidad, la Ley Orgánica 8/2013, de 9 de diciembre, para la mejora de la calidad educativa (LOMCE, 2013) ha modificado las 8 competencias básicas previas en 7 competencias clave. En torno a la competencia se han generado multitud de publicaciones tendentes a delimitar su definición y a establecer distintas características y categorías. A pesar de ello, De la Orden (2011, p.10) manifiesta la dificultad de plantear un cuerpo teórico sobre el término competencia, pues a pesar de la preocupación generalizada, "la actual literatura sobre competencias carece de una base conceptual y analítica y no existe un reconocimiento explícito de la necesidad de programas de investigación tendentes a promover una mejor comprensión de la naturaleza de la competencia, cómo desarrollarla en los alumnos, cómo puede ser evaluada y cuál puede ser el impacto que tendría en los estudiantes, en las organizaciones educativas y en la sociedad en general».

La complejidad, no solo del concepto de competencia sino también del derivado educación basada en competencias, requiere a juicio de Mulder (2004) no centrarse en una definición hermética y partir de una idea flexible de la competencia. Por otra parte, el estudio llevado a cabo por Merriënboer, Klink y Hendriks (2002) pretendía integrar diferentes perspectivas en torno a la competencia, tanto en un nivel teórico como práctico. En este sentido, delimitaron 6 características de la competencia: vinculación a un contexto, indivisibilidad de la unión entre conocimientos, destrezas y actitudes, sometimiento a cambios, conexión a tareas y actividades, requerimiento de aprendizaje y desarrollo, e interrelación entre competencias.

Por su parte, el proyecto Design and Selection of Competencies (DeSeCo) OCDE-DESECO, 2002 determinó la existencia de un conjunto de competencias clave que debían desarrollarse a lo largo de la etapa obligatoria. De este modo, se identificaban 3 competencias básicas, desglosadas en otras más específicas. Estas eran las siguientes: en primer lugar, actuar con autonomía (actuar desde una perspectiva global, con el objetivo de definir y desarrollar planes y proyectos personales, para afirmar y defender derechos, intereses, límites y necesidades). En segundo lugar, habilidad para utilizar de forma interactiva la lengua, los símbolos y los textos, el conocimiento y la información, y la tecnología. En tercer lugar, interactuar en grupos heterogéneos (para relacionarse bien con otros, para cooperar con otros y para manejar y resolver conflictos).

La consecuencia de este proyecto fue la publicación de la Recomendación del Parlamento Europeo y del Consejo de 18 de diciembre de 2006 (Recomendación del Parlamento Europeo y del Consejo, 2006)sobre las competencias clave para el aprendizaje permanente (2006/962/CE), que definió la competencia como «una combinación de conocimientos, capacidades y actitudes adecuadas al contexto" y fijó la existencia de 8 competencias básicas: en comunicación lingüística, matemática, conocimiento e interacción con el mundo físico, tratamiento de la información y competencia digital, social y ciudadana, cultural y artística, para aprender a aprender, autonomía e iniciativa personal.

Si bien la competencia mediática no es considerada como una de estas 8 competencias clave, esta ha cobrado una gran importancia en los últimos tiempos. Así, en lo que concierne al término competencia mediática, competencia en medios de comunicación, competencia en comunicación o competencia audiovisual, como se la ha denominado en diferentes contextos, esta se ha convertido en centro de interés por parte de distintos investigadores, debido fundamentalmente al imparable desarrollo de las tecnologías de la información y la comunicación y la omnipresencia de los medios de comunicación en nuestras vidas, así como a la preocupación de los poderes públicos por propiciar una educación que incluya los aspectos distintivos de esta competencia.

Autorías como Bazalgette, Bevort, Buckingham, Carlsson, Piette, Tisseron o Verniers apuntaron la necesidad de que la competencia mediática se convirtiera en una competencia básica adquirida por toda la ciudadanía en el II Congreso Media Literacy in Europe: Controversies, challenges and perspectives (Italia, 2009). Un paso más allá lo dio Buckingham (citado en Aguaded et al., 2011, p. 19-20) al detallar los aspectos claves que la definirían: habilidades en el manejo de la tecnología; aprecio de la herencia europea audiovisual; protección de los niños ante contenidos nocivos y del desarrollo de su conciencia ante los riesgos en la Red; inclusión de grupos hasta ahora excluidos en el uso de la tecnología; resistencia a la persuasión comercial y sensibilización en la comercialización de nuevas prácticas; fomento de la ciudadanía activa y participación en la sociedad civil; promoción de la libre creatividad y la expresión artística mediante el uso de nuevos medios de comunicación y posibilidad de las personas de comunicarse con el público.

Por su parte, Ferrés elaboró el documento Competencias en comunicación audiovisual, en el que se define competencia en comunicación audiovisual como «la capacidad del individuo para interpretar y analizar desde la reflexión crítica las imágenes y los mensajes audiovisuales y para expresar con una mínima corrección en el ámbito comunicativo" (Ferrés, 2007, p. 102). En este sentido, González, Sedeño y Gozálvez (2012, p. 122) entienden que «la competencia audiovisual está íntimamente relacionada con la competencia mediática, de modo que pueden incluso identificarse ambas categorías en un entorno en el que es fundamental el conocimiento de los medios de comunicación y de las tecnologías multimedia».

En una segunda fase del trabajo iniciado por Ferrés, se ha llevado a cabo una investigación sobre el grado de competencia mediática que poseía la ciudadanía en España (Ferrés et al., 2011), así como en Andalucía (Aguaded et al., 2011) y en Aragón (Gabelas y Marta, 2011), entre otras comunidades autónomas. Estas investigaciones han puesto de manifiesto una mayor necesidad de formación de la ciudadanía en medios de comunicación. La propia Unión Europea reclama una alfabetización en dichos medios a través de la Directiva 2007/65/CE, que establece en su artículo 37 lo siguiente:

«La alfabetización mediática abarca las habilidades, los conocimientos y las capacidades de comprensión que permiten a los consumidores utilizar con eficacia y seguridad los medios. Las personas competentes en el uso de los medios podrán elegir con conocimiento de causa, entender la naturaleza de los contenidos y los servicios, aprovechar toda la gama de oportunidades ofrecidas por las nuevas tecnologías de la comunicación y proteger mejor a sus familias y a sí mismas frente a los contenidos dañinos u ofensivos. Por lo tanto, se debe promover el desarrollo de la alfabetización mediática en todos los sectores de la sociedad y seguirse de cerca sus avances». Diario Oficial de la Unión Europea. Directiva 2007/65/CE del Parlamento Europeo y del Consejo de 11 de diciembre de 2007 (http://eur-ex.europa.eu/lexUriServ/lexUriServ.do?uri=OJ:L:2007: 332:0027:0045:ES:PDF).

Estas investigaciones han puesto de manifiesto el grado de competencia mediática que alcanzaba la ciudadanía en su conjunto, al tiempo que han servido para que Ferrés y Piscitelli (2012) establezcan 6 dimensiones junto con sus correspondientes indicadores identificativos de la competencia mediática y que se vinculan con el ámbito de participación como personas que reciben mensajes e interactúan (ámbito del análisis) y como personas que producen mensajes (ámbito de la expresión). Pero ¿qué ocurre en los centros escolares?, ¿se está capacitando al alumnado para ejercer esta ciudadanía crítica con los medios?

El interrogante de investigación planteado considera las afirmaciones realizadas por Ferrés, Aguaded y Aparici (2013), Aparici, Campuzano, Ferrés y García (2010), Camps (2009) y Tucho (2008), y sobre la escasa presencia de la competencia mediática en el currículo de las etapas de enseñanza obligatoria, pero ¿cuál es la presencia real de la competencia mediática en el currículo del alumnado de cuarto de Educación Primaria?, ¿y concretamente en sus criterios de evaluación? 
El objetivo, por tanto, de esta investigación es determinar cuantitativamente la presencia de los descriptores de la competencia mediática en los criterios de evaluación de cuarto curso de Educación Primaria en el currículo de las 17 comunidades autónomas.

\section{Método}

La metodología seguida en este estudio se basa fundamentalmente en el análisis de contenido. Este se ubica, según López (2002, p. 174), «en el ámbito de la investigación descriptiva» y pretende «descubrir los componentes básicos de un fenómeno determinado extrayéndolos de un contenido dado a través de un proceso que se caracteriza por el intento de rigor en la medición».

\section{Unidades de análisis}

En este estudio la unidad de análisis ha quedado configurada del siguiente modo: en primer lugar, una unidad de registro de base gramatical constituida por frases y párrafos; en segundo lugar, una unidad de contexto conformada por textos legales de todas las comunidades autónomas de España y, en tercer lugar, la existencia o no de las categorías que más adelante se explicitan, así como la cuantificación de su presencia.

Los materiales empleados fueron los 17 textos legales -decretos u órdenes- que desarrollan el currículum de la etapa de Educación Primaria en cada comunidad autónoma. De ellas se han extraído los objetivos de etapa y área, contenidos del cuarto curso de esta etapa de todas las áreas, así como los criterios de evaluación correspondientes. De este modo, la generalización de los resultados se extendía al currículo de este nivel educativo en todas las comunidades autónomas. En este nivel educativo se realizan las pruebas de diagnóstico estatal sobre el grado que alcanza el alumnado en diferentes competencias, entre las que no aparece la competencia mediática, por ello se hacía necesario ubicar esta investigación en dicho nivel y no al finalizar la etapa de Educación Primaria.

El resultado ha sido la obtención de una población de 4.935 unidades de registro; de ellas, 1.428 correspondían a los criterios de evaluación, elemento curricular que analizamos en estas páginas.

\section{Procedimiento}

La normativa se extrajo de las páginas web oficiales de las 17 comunidades autónomas, de este modo se aseguraba el trabajo con la fuente original. Los criterios de inclusión utilizados fueron: la nomenclatura de currículo de Educación Primaria, la vigencia de la publicación y su vinculación con la Ley Orgánica 2/2006, de 3 de mayo, de Educación y que representara a cada comunidad autónoma. La fecha de búsqueda tuvo lugar entre los meses de febrero y marzo de 2011.

\section{Análisis de la información}

De forma previa al análisis de la información se realizó la codificación de las unidades de registro atendiendo a la comunidad autónoma, al elemento curricular al que hacía referencia y al número de orden que se le proporcionaba en la normativa. En este caso, se seleccionaron las relativas a los criterios de evaluación (ejemplo, ANCE001). La elección de este elemento curricular específico se debe a que Tiana (2011, p. 71) puntualiza que «los currículos estatales han traducido las competencias básicas en forma de criterios de evaluación para cada área y materia [...] la formulación de dichos criterios en los reales decretos que regulan las enseñanzas mínimas se ha hecho de tal modo que refuerce la orientación hacia el desarrollo de competencias». De este modo, los criterios de evaluación pueden reflejar claramente la presencia o ausencia de la competencia mediática en el currículum escolar.
La siguiente fase fue el establecimiento de unos criterios de búsqueda para diferenciar los criterios de evaluación que hacían referencia a la competencia mediática de los que no, de este modo, se redujeron a 314 las unidades de registro. Los términos de búsqueda se seleccionaron de acuerdo con las dimensiones, subdimensiones y descriptores establecidos por Ferrés (2006, 2007) para definir la competencia mediática. Algunos ejemplos fueron: medios, comunicación, sonido, imagen, periódico, Internet o web, entre otros.

Seguidamente se efectuó un análisis comparativo de los criterios de evaluación de cada área de conocimiento por separado - Lengua Castellana (LM), Matemáticas (MA), Conocimiento del Medio (CM), Educación Artística (EA), Educación Física (EF), Lengua Extranjera (LE) y Segunda Lengua Extranjera (L2) - en cada comunidad autónoma, al objeto de determinar similitudes entre ellos y reducir aún más las unidades de registro. Para ello se diseñó una tabla de doble entrada para cada área: en las columnas se consignaban las comunidades autónomas y en las filas los criterios de evaluación, en la intersección se marcaba la presencia de dicho criterio en la comunidad o comunidades autónomas correspondientes.

Una vez reducidas las unidades de registro, se procedió a su recodificación teniendo en cuenta las comunidades autónomas que lo incorporaban, el elemento curricular analizado y la numeración seguida en la normativa (ejemplo ANCANCE001_009).

Estas unidades de registro fueron introducidas en el programa ATLAS.ti y se fueron categorizando en función de los 55 descriptores establecidos por Ferrés y Piscitelli (2012) para las 6 dimensiones que definen la competencia mediática: lenguajes, tecnología, procesos de interacción, procesos de producción y difusión, ideología y valores y estética. Este proceso fue realizado de manera independiente por 3 miembros del proyecto de investigación siguiendo las recomendaciones de Krippendorf (1997, pp.194-195). Para obtener un mayor grado de fiabilidad, esta se situó en un $70 \%$ de acuerdo con la escala porcentual de Fox (1981). En lo que concierne a la validez del estudio, se estableció una validez de contenido (Fox, 1981) basada en la experiencia profesional de los jueces codificadores con el currículo escolar y la propuesta realizada por Ferrés y Piscitelli (2012).

Una vez establecida esta categorización, se procedió a comprobar si los maestros en ejercicio establecían una vinculación entre los criterios de evaluación seleccionados y los descriptores de la competencia mediática. Para ello se presentó a 10 participantes la codificación realizada mediante una tabla en la que aparecían 4 columnas: en la primera el criterio de evaluación, en la segunda el descriptor con el que los jueces codificadores lo habían vinculado, en la tercera se ofrecía la posibilidad de marcar sí o no a dicha relación y en la cuarta se permitía registrar una opción alternativa de acuerdo con un documento anexo en el que estaban recogidos los 55 descriptores establecidos para la competencia mediática.

El tratamiento de este análisis se realizó en una hoja de cálculo en la que se consignaba la frecuencia y el porcentaje de relación, desechando aquellos resultados que no alcanzaban el $70 \%$ de acuerdo. Todo este proceso se llevó a cabo entre abril de 2011 y octubre de 2012.

\section{Resultados}

Uno de los problemas que se ha puesto de manifiesto en los estudios sobre la competencia mediática en el ámbito educativo es su reducida presencia en los currículos, como ya se ha expresado. Sin embargo, es necesario explicitarlo con evidencias concretas.

En este sentido, de los 55 descriptores que describen la competencia mediática, 36 han quedado identificados en los criterios de evaluación de las áreas que integran el currículo de cuarto curso de Educación Primaria: CM, EA, EF, LC, LE, MA y L2. Este número 


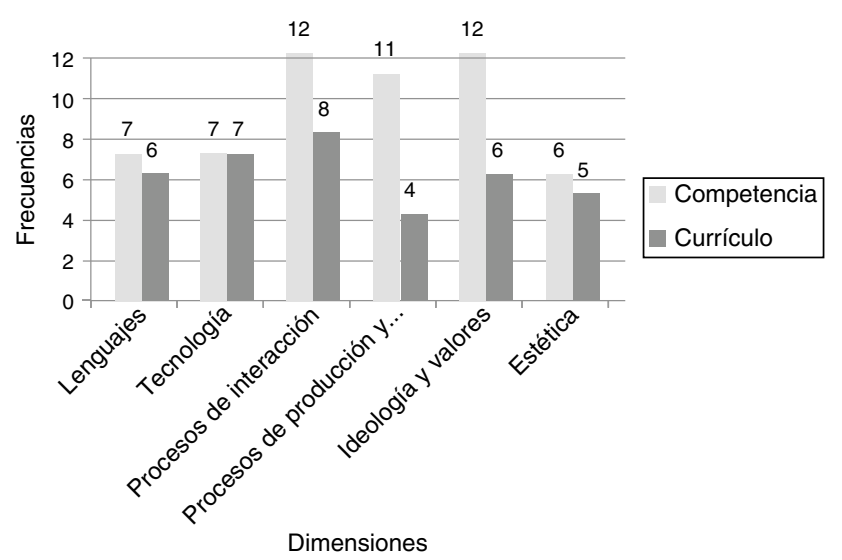

Figura 1. Presencia de los criterios de evaluación en los descriptores de la competencia mediática.

Fuente: Elaboración propia.

supone que el 65,45\% de los aspectos distintivos de la competencia mediática se encuentra presente en estos criterios, pero ¿cómo se encuentra distribuida dicha presencia? En la figura 1 se aprecia la comparación entre los 55 descriptores propuestos para la competencia mediática y los hallados en los criterios de evaluación. Las mayores diferencias entre ambos se aprecian en 3 dimensiones: procesos de interacción, procesos de producción y difusión e ideología $y$ valores.

Por su parte, la figura 2 destaca 3 cuestiones esenciales. Por un lado, el predominio de los procesos de análisis frente a los de expresión en las dimensiones lenguajes, procesos de interacción e ideologías y valores; por otro, la supremacía de los procesos de expresión, en contraposición a los de análisis en las dimensiones tecnología, procesos de producción y difusión y estética; y, finalmente, la única existencia de procesos de análisis en la dimensión ideología $y$ valores.

De forma más detallada, en las tablas 1-6 se muestran las frecuencias y los porcentajes de criterios de evaluación de las distintas áreas del currículo de cuarto de Educación Primaria relacionados con los descriptores de la competencia mediática en cada una de sus dimensiones.

Las áreas de CM y LC son las que mayor presencia manifiestan en la dimensión lenguajes, seguidas de EA, LE, MA y L2 (tabla 1).

Algunos de los ejemplos se muestran a continuación:

En CM cabría mencionar obtener información a partir de planos, mapas, esquemas, gráficos e imágenes y descubrir y explicar la información que contienen (vinculación L1a) y comunicar

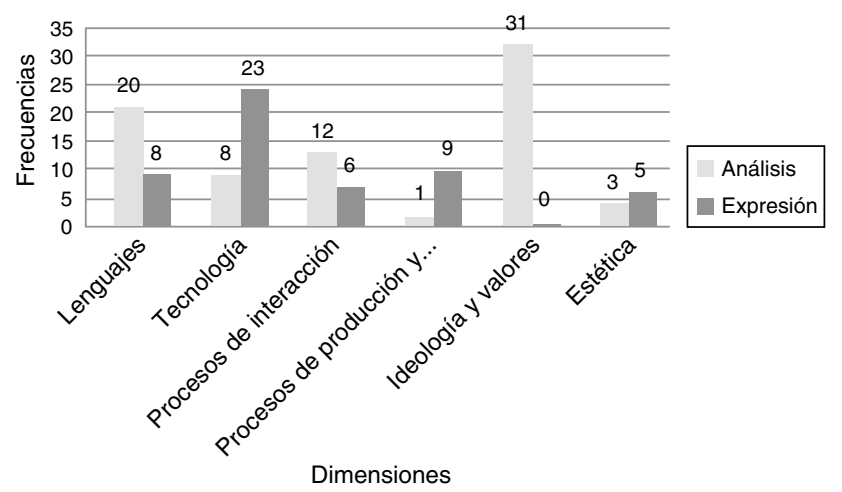

Figura 2. Distribución de los criterios de evaluación en función de las dimensiones de la competencia digital.

Fuente: Elaboración propia. informaciones de forma oral y escrita, acompañándolas de imágenes, tablas, gráficos o esquemas, estableciendo conclusiones coherentes, y mostrando sentido estético en la presentación (L1e).

En el caso de EA, se podrían identificar y verbalizar con la terminología adecuada las posibilidades plásticas, sonoras y corporales que utilizan los artistas y los medios de comunicación presentes en el entorno (L3a).

El área de LC se ejemplifica con los criterios relativos a localizar información concreta y realizar inferencias directas en la lectura de textos: reconocer aspectos no estrictamente textuales (títulos, imágenes, tamaño y tipo de letra) y aplicar estrategias de lectura comprensiva (L1a) y redactar los textos propios de las relaciones interpersonales en el aula (cartas, normas de convivencia, avisos, solicitudes...), así como otros propios de los medios de comunicación social, referidos a hechos próximos a la experiencia (noticia, entrevista, reseña de libros o música, cartas al director, etc.) (L2e).

El criterio de evaluación que se destaca del área de LE es planificar y redactar textos escritos (cartas, instrucciones, diarios, email...) con progresiva adecuación pragmática y morfosintáctica, atendiendo al destinatario, al tipo de texto y a la finalidad, tanto en soporte papel como digital (L2e), mientras que el de la 2L es leer y captar el sentido global e informaciones específicas en textos orales con ayuda de elementos lingüísticos y no lingüísticos (L2a).

Las MA muestran como ejemplo representar los datos de un problema mediante gráficos, flechas, diagramas o tablas de doble entrada (L1e).

Por su parte, en la dimensión tecnología, las áreas de LC y CM ocupan el primer lugar en cuanto a presencia de los descriptores de la competencia digital, seguidas de la EA, LE y MA (tabla 2).

Los criterios de evaluación más significativos son los expresados a continuación:

Para el área de CM destacan descubrir cambios de las comunicaciones y los cambios que las comunicaciones, la tecnología, las telecomunicaciones y la informática han supuesto en las actividades personales, económicas y sociales (T1a) y construir algún texto utilizando las herramientas tecnológicas (T1e).

En la de EA cabría mencionar manipular y modificar de modo simple, mediante aplicaciones informáticas, imágenes y sonidos según el efecto deseado o sugerido y archivarlos para un uso posterior (T3e).

Por su parte, EF muestra como ejemplo conocer sitios web para localizar información sobre temas propios y crear su lista de favoritos (T4a).

El área de LC se ejemplifica en utilizar las tecnologías de la información y la comunicación como herramienta de producción, comprensión y expresión y para adquirir nuevos aprendizajes (T1e).

En lo que concierne a LE el criterio seleccionado es utilizar las funciones básicas de un procesador de textos para la edición y corrección de textos (T1e). Mientras que en la L2 es escribir en soporte papel y digital frases y textos cortos de situaciones cotidianas (T1e).

Por último, en el área de MA el ejemplo más destacado alude a aplicar herramientas tecnológicas conocidas a nuevas tareas en el proceso de aprendizaje: editores gráficos, aplicaciones del portal educativo, tecnologías de la información y comunicación, Internet, etc. (T1e).

En cuanto a la dimensión procesos de interacción, las áreas CM y EF encabezan la mayor relación con sus descriptores, seguidas de LC y LE (tabla 3).

Como ejemplo se mencionan los siguientes criterios de evaluación:

En CM, discernir actividades que perjudican y favorecen la salud, con especial dedicación en el uso limitado de televisión, videoconsolas y juegos de ordenador (I1e). En el área de EF, tomar conciencia de los riesgos que un uso abusivo de los soportes 
Tabla 1

Frecuencias y porcentajes de la dimensión 1. Lenguajes

\begin{tabular}{|c|c|c|c|c|c|c|c|c|}
\hline Descriptores & $\mathrm{CM}$ & EA & $\mathrm{EF}$ & LC & LE & MA & L2 & $\%$ \\
\hline \multicolumn{9}{|l|}{ Análisis } \\
\hline $\begin{array}{l}\text { L1a. Capacidad de interpretar y de valorar los diversos códigos de } \\
\text { representación y la función que cumplen en un mensaje }\end{array}$ & 1 & 2 & & 2 & 2 & 1 & & 5,55 \\
\hline $\begin{array}{l}\text { L2a. Capacidad de analizar y de valorar los mensajes desde la perspectiva del } \\
\text { significado y del sentido, de las estructuras narrativas y de las convenciones } \\
\text { de género y de formato }\end{array}$ & 3 & & & 2 & 1 & 1 & 1 & 6,35 \\
\hline $\begin{array}{l}\text { L3a. Capacidad de comprender el flujo de historias y de informaciones } \\
\text { procedentes de múltiples medios, soportes, plataformas y modos de } \\
\text { expresión }\end{array}$ & 1 & 1 & & & & 1 & & 2,38 \\
\hline $\begin{array}{l}\text { L4a. Capacidad de establecer relaciones entre textos -intertextualidad-, } \\
\text { códigos y medios, elaborando conocimientos abiertos, sistematizados e } \\
\text { interrelacionados }\end{array}$ & & 1 & & 1 & & & & 1,78 \\
\hline \multicolumn{9}{|l|}{ Expresión } \\
\hline $\begin{array}{l}\text { L1e. Capacidad de expresarse mediante una amplia gama de sistemas de } \\
\text { representación y de significación }\end{array}$ & 2 & & & 1 & 1 & 1 & & 3,96 \\
\hline $\begin{array}{l}\text { L2e. Capacidad de elegir entre distintos sistemas de representación y distintos } \\
\text { estilos en función de la situación comunicativa, del tipo de contenido que } \\
\text { hay que transmitir y del tipo de interlocutor }\end{array}$ & & 1 & & 1 & 1 & & & 2,38 \\
\hline Total & 7 & 5 & 0 & 7 & 5 & 4 & 1 & 28,57 \\
\hline
\end{tabular}

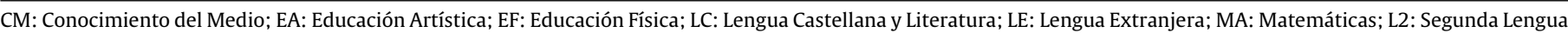
Extranjera.

Fuente: Elaboración propia.

digitales, videojuegos, móviles y demás pantallas de visualización de datos pueden generar para la salud (I1a).

El ámbito de las lenguas se ejemplifica del siguiente modo: en LC destaca captar el sentido de los textos orales de uso habitual (familia, radio, televisión...) reconociendo las ideas principales y secundarias, distinguiendo las diferencias entre información y opinión (I3a); en LE sobresale utilizar las tecnologías de la información y la comunicación para realizar comunicaciones orales y escritas con otras personas (I3e) y en la L2 establecer contactos con hablantes de la lengua francesa a través de mensajes electrónicos, páginas web, etc., y otros soportes que ofrecen las TIC mediante diversas tareas (I3e).

En lo que concierne a la dimensión procesos de producción y difusión, nuevamente el área de $\mathrm{CM}$ es la que mayor vinculación mantiene con la competencia mediática. El segundo lugar lo ocupa el área de LE, seguida de LC (tabla 4).

A continuación se propone la ejemplificación de los criterios de evaluación:

El área de CM se hace patente con el criterio de utilizar las tecnologías de la información y la comunicación (correo electrónico, chat, foros, etc.) como herramienta de comunicación y aprendizaje $\mathrm{y}$ de hacer un uso responsable de ellas (P3e).

Las áreas de LC y la LE quedan representadas respectivamente en los siguientes criterios: usar un programa de correo electrónico para leer, responder, redactar, enviar, imprimir y guardar mensajes con el fin de establecer relaciones interpersonales (P3e) y buscar, recopilar, organizar, presentar y compartir la información en distintos soportes sobre los países, culturas, etc. (P3e).

En la dimensión ideología y valores se evidencia la presencia de la competencia en los criterios de evaluación de todas las áreas del currículo del alumnado de cuarto de Educación Primaria. En esta ocasión, el área de LC muestra la mayor representación de la competencia mediática en las áreas curriculares. En segundo lugar, CM consigue también una importante vinculación de sus criterios de evaluación con los descriptores de la competencia (tabla 5).

Los criterios de evaluación que se proponen como ejemplo son los siguientes:

En CM destacaría analizar los mensajes publicitarios sobre la vida de las personas, procesos de los bienes, productos y servicios

Tabla 2

Frecuencias y porcentajes de la dimensión 2. Tecnología

\begin{tabular}{|c|c|c|c|c|c|c|c|c|}
\hline Descriptores & $\mathrm{CM}$ & EA & $\mathrm{EF}$ & LC & LE & MA & $\mathrm{L} 2$ & $\%$ \\
\hline \multicolumn{9}{|l|}{ Análisis } \\
\hline $\begin{array}{l}\text { T1a. Comprensión del papel que desempeñan en la sociedad las tecnologías de } \\
\text { la información y de la comunicación y de sus posibles efectos }\end{array}$ & 2 & & & & & & & 1,78 \\
\hline $\begin{array}{l}\text { T2a. Habilidad para interactuar de manera significativa con medios que } \\
\text { permiten expandir las capacidades mentales }\end{array}$ & & & 1 & & & & & 0,79 \\
\hline $\begin{array}{l}\text { T3a. Capacidad de manejo de las innovaciones tecnológicas que hacen posible } \\
\text { una comunicación multimodal y multimedial }\end{array}$ & & 2 & & 2 & & & & 3,17 \\
\hline $\begin{array}{l}\text { T4a. Capacidad de desenvolverse con eficacia en entornos hipermediales, } \\
\text { transmediáticos y multimodales }\end{array}$ & & & 1 & & & & & 0,79 \\
\hline \multicolumn{9}{|l|}{ Expresión } \\
\hline $\begin{array}{l}\text { T1e. Capacidad de manejar con corrección herramientas comunicativas en un } \\
\text { entorno multimedial y multimodal }\end{array}$ & 4 & 1 & & 2 & 2 & 1 & 1 & 8,73 \\
\hline $\begin{array}{l}\text { T2e. Capacidad de adecuar las herramientas tecnológicas a los objetivos } \\
\text { comunicativos que se persiguen }\end{array}$ & & 1 & 1 & 3 & 2 & 3 & 1 & 8,73 \\
\hline $\begin{array}{l}\text { T3e. Capacidad de elaborar y de manipular imágenes y sonidos desde la } \\
\text { conciencia de cómo se construyen las representaciones de la realidad }\end{array}$ & & 1 & & & & & & 0,79 \\
\hline Total & 6 & 5 & 3 & 7 & 4 & 4 & 2 & 31,63 \\
\hline
\end{tabular}

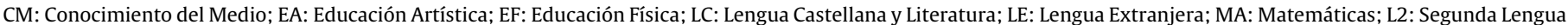
Extranjera.

Fuente: Elaboración propia. 
Tabla 3

Frecuencias y porcentajes de la dimensión 3. Procesos de interacción

\begin{tabular}{|c|c|c|c|c|c|c|c|c|}
\hline Descriptores & $\mathrm{CM}$ & EA & $\mathrm{EF}$ & LC & LE & MA & L2 & $\%$ \\
\hline \multicolumn{9}{|l|}{ Análisi } \\
\hline $\begin{array}{l}\text { I1a. Capacidad de selección, de revisión y de autoevaluación de la propia dieta } \\
\text { mediática, en función de unos criterios conscientes y razonables }\end{array}$ & 2 & & 2 & 1 & & & & 3,96 \\
\hline $\begin{array}{l}\text { I2a. Capacidad de dilucidar por qué gustan unos medios, unos productos o } \\
\text { unos contenidos, por qué tienen éxito, individual o colectivamente: qué } \\
\text { necesidades y deseos satisfacen en lo sensorial, en lo emotivo, en lo } \\
\text { cognitivo, en lo estético, en lo cultural, etc. }\end{array}$ & 1 & & & & & & & 0,79 \\
\hline $\begin{array}{l}\text { I3a. Capacidad de discernir y de gestionar las disociaciones que se producen a } \\
\text { veces entre sensación y opinión, entre emotividad y racionalidad }\end{array}$ & & & & 1 & & & & 0,79 \\
\hline $\begin{array}{l}\text { I4a. Capacidad de apreciar los mensajes provenientes de otras culturas para el } \\
\text { diálogo intercultural en un período de medios transfronterizos }\end{array}$ & 1 & & & & & & & 0,79 \\
\hline $\begin{array}{l}\text { I5a. Capacidad de gestionar el ocio mediático convirtiéndolo en oportunidad } \\
\text { para el aprendizaje }\end{array}$ & 1 & & 2 & 1 & & & & 3,17 \\
\hline \multicolumn{9}{|l|}{ Expresión } \\
\hline $\begin{array}{l}\text { I1e. Actitud activa en la interacción con las pantallas, entendidas como } \\
\text { oportunidad para construir una ciudadanía más plena, un desarrollo } \\
\text { integral, para transformarse y para transformar el entorno }\end{array}$ & & & 1 & & & & & 0,79 \\
\hline $\begin{array}{l}\text { I2e. Capacidad de llevar a cabo un trabajo colaborativo mediante la } \\
\text { conectividad y la creación de plataformas que facilitan las redes sociales }\end{array}$ & & & & & 1 & & & 0,79 \\
\hline $\begin{array}{l}\text { I3e. Capacidad de interaccionar con personas y con colectivos diversos en } \\
\text { entornos cada vez más plurales y multiculturales }\end{array}$ & & & & & 2 & & 2 & 3,17 \\
\hline Total & 5 & 0 & 5 & 3 & 3 & 0 & 2 & 18,36 \\
\hline
\end{tabular}

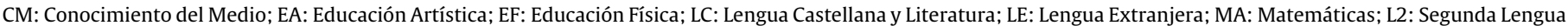
Extranjera.

Fuente: Elaboración propia.

(V1a), mientras que en EA lo haría identificar estereotipos en imágenes presentes en su medio o percibidas a través de la publicidad (V5a)y en el área de EF opinar coherente y críticamente con relación a las situaciones conflictivas surgidas en la práctica de la actividad física y el deporte presentadas a través de los medios de comunicación o de las tecnologías de la información y la comunicación (V6a).

El área de LC muestra 2 ejemplos claves: informarse sobre hechos próximos a su experiencia en los medios de comunicación a través de las tecnologías de la información y la comunicación y otras fuentes (V3a) y captar el sentido de textos orales de uso habitual (familia, radio, televisión, etc.), interpretando el significado de elementos no explícitos como el doble sentido y adoptando una actitud crítica (V4a).

La representación en la LE y la L2 se revela respectivamente en los criterios de utilizar las tecnologías de la información y comunicación para contrastar y comprobar información (V3a) y usar estrategias para aprender a aprender: uso de las TIC e Internet, diccionarios visuales, etc. (V3a).
En el área de MA se recoge como ejemplo el criterio que evalúa la capacidad de interpretar distintas informaciones estadísticas, provenientes de los medios de comunicación (V3a).

Finalmente, en la dimensión estética la presencia de la competencia mediática se centra exclusivamente en el área de EA, algo totalmente lógico al tratarse del ámbito de conocimiento propio del área. Como ejemplos se podrían citar la evaluación de las capacidades desarrollar la sensibilidad estética y educacional como público al mostrar interés por conocer profesiones vinculadas a los ámbitos artísticos (E2a) y experimentar con las posibilidades artísticas de los medios audiovisuales y digitales (E1e). No obstante, el área de CM también aporta un criterio a esta dimensión (tabla 6).

\section{Discusión y conclusiones}

Si hiciésemos un recorrido por la literatura generada en torno a los medios de comunicación, observaríamos cómo desde un principio se ha planteado la necesidad de incorporarlos al ámbito

Tabla 4

Frecuencias y porcentajes de la dimensión 4. Procesos de producción y difusión

\begin{tabular}{|c|c|c|c|c|c|c|c|c|}
\hline Descriptores & $\mathrm{CM}$ & EA & $\mathrm{EF}$ & LC & LE & MA & $\mathrm{L} 2$ & $\%$ \\
\hline \multicolumn{9}{|l|}{ Análisis } \\
\hline $\begin{array}{l}\text { P1a. Conocimiento de las diferencias básicas entre las producciones } \\
\text { individuales y las colectivas, entre las populares y las corporativas, y, en el } \\
\text { ámbito de estas últimas, si es el caso, entre las elaboradas por instancias de } \\
\text { titularidad pública y privada }\end{array}$ & 1 & & & & & & & 0,79 \\
\hline \multicolumn{9}{|l|}{ Expresión } \\
\hline $\begin{array}{l}\text { P1e. Conocimiento de las fases de los procesos de producción y de la } \\
\text { infraestructura necesaria para producciones de carácter personal, grupal o } \\
\text { corporativo }\end{array}$ & 1 & & & 1 & 2 & & & 3,17 \\
\hline $\begin{array}{l}\text { P2e. Capacidad de trabajar, de manera colaborativa, en la elaboración de } \\
\text { productos multimedia o multimodales }\end{array}$ & 1 & & & & & & & 0,79 \\
\hline $\begin{array}{l}\text { P3e. Capacidad de compartir y diseminar información, a través de los medios } \\
\text { tradicionales y de las redes sociales, incrementando la visibilidad de los } \\
\text { mensajes, en interacción con comunidades cada vez más amplias }\end{array}$ & 2 & & & 1 & 2 & & & 3,17 \\
\hline Total & 5 & 0 & 0 & 2 & 4 & 0 & 0 & 10,2 \\
\hline
\end{tabular}

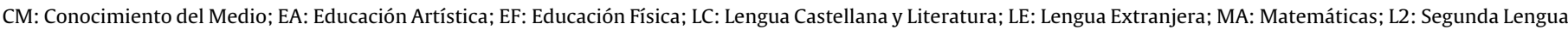
Extranjera.

Fuente: Elaboración propia. 
Tabla 5

Frecuencias y porcentajes de la dimensión 5. Ideología y valores

\begin{tabular}{|c|c|c|c|c|c|c|c|c|}
\hline Descriptores & $\mathrm{CM}$ & EA & $\mathrm{EF}$ & LC & LE & MA & L2 & $\%$ \\
\hline \multicolumn{9}{|l|}{ Análisis } \\
\hline $\begin{array}{l}\text { V1a. Capacidad de descubrir la manera en que las representaciones mediáticas } \\
\text { estructuran nuestra percepción de la realidad, a menudo mediante } \\
\text { comunicaciones inadvertidas }\end{array}$ & 1 & & & & & & & 0,79 \\
\hline $\begin{array}{l}\text { V2a. Capacidad de evaluar la fiabilidad de las fuentes de información, } \\
\text { extrayendo conclusiones críticas tanto de lo que se dice como de lo que se } \\
\text { omite }\end{array}$ & 1 & & & & 2 & & & 3,17 \\
\hline $\begin{array}{l}\text { V3a. Habilidad para buscar, organizar, contrastar, priorizar y sintetizar } \\
\text { informaciones procedentes de distintos sistemas y de diferentes entornos }\end{array}$ & 4 & 1 & 2 & 6 & 2 & 1 & 1 & 13,49 \\
\hline $\begin{array}{l}\text { V4a. Capacidad de detectar las intenciones o intereses que subyacen tanto en } \\
\text { las producciones corporativas como en las populares, así como su ideología y } \\
\text { valores, explícitos o latentes, adoptando una actitud crítica ante ellos }\end{array}$ & 1 & & 1 & 2 & 1 & & & 4,76 \\
\hline $\begin{array}{l}\text { V5a. Capacidad de analizar las identidades virtuales individuales y colectivas, y } \\
\text { de detectar los estereotipos, sobre todo en cuanto a género, raza, etnia, clase } \\
\text { social, religión, cultura, discapacidades, etc., analizando sus causas y } \\
\text { consecuencias }\end{array}$ & & 1 & & 1 & & & & 1,78 \\
\hline $\begin{array}{l}\text { V6a. Capacidad de gestionar las propias emociones en la interacción con las } \\
\text { pantallas, en función de la ideología y de los valores que se transmiten en } \\
\text { ellas }\end{array}$ & & & 1 & & & & & 7,14 \\
\hline Total & 7 & 2 & 4 & 9 & 5 & 1 & 1 & 31,63 \\
\hline
\end{tabular}

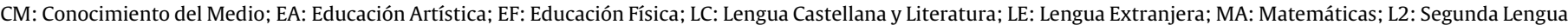
Extranjera.

Fuente: Elaboración propia.

educativo, debido a las potencialidades educativas que se les atribuyen. Actualmente, el discurso se mantiene vivo (Moral, 2006; Pérez y López, 2007) y autores como Scheuer (2009, p.15) manifiestan que «desde hace más de 20 años, educadores de todo el mundo han hecho campaña a favor de la educación en medios; sin embargo, en la mayoría de los países, los responsables de las políticas educativas nacionales no han advertido hasta muy recientemente la importancia de la alfabetización mediática».

Nuestro sistema educativo, inmerso en la dinámica europea, ha iniciado recientemente una reforma que, junto a la calidad y la equidad de la educación, encuentra en las competencias básicas el eje rector de su nueva configuración y del currículo escolar, entendido este, de acuerdo con el artículo 5 del Real Decreto 1513/06 (Real Decreto, 2006), como «el conjunto de objetivos, competencias básicas, contenidos, métodos pedagógicos y criterios de evaluación de esta etapa educativa».

En este último elemento se ha centrado este artículo con el objetivo de delimitar la presencia o ausencia de la competencia mediática en el currículo escolar. En el análisis realizado, la evidencia de su existencia en él se ha cifrado en un $65,45 \%$, lo que supone un porcentaje importante en el cuarto curso de la etapa de Educación Primaria.
En este análisis, de acuerdo con lo manifestado por Tucho (2008), se destacan 2 enfoques que se desprenden del análisis de la normativa estatal y autonómica: por un lado, la consideración de los medios de comunicación como instrumentos de apoyo a los procesos de enseñanza y aprendizaje; por otro lado, la necesidad de un análisis de estos desde una perspectiva crítica y desde su repercusión social.

El primer enfoque ha sido el que, de manera tradicional, se ha generalizado en el currículo escolar, quedando el segundo a la buena voluntad del profesorado, sobre todo a partir de la incorporación de las tecnologías de la información y la comunicación a dicho currículo. Sin embargo, la propuesta presentada da un paso más en esta visión polarizada de la presencia de los medios de comunicación en la normativa educativa.

Al partir de una delimitación de la competencia mediática en 6 dimensiones y 2 ámbitos de desarrollo -análisis y expresión-. se posibilita su análisis pormenorizado en los criterios de evaluación, destacando que, si bien no todos los descriptores de la competencia mediática quedan vinculados con los criterios de evaluación del currículo del alumnado de cuarto de educación primaria, todas las dimensiones quedan reflejadas en dichos criterios.

Tabla 6

Frecuencias y porcentajes de la dimensión 6. Estética

\begin{tabular}{|c|c|c|c|c|c|c|c|c|}
\hline Descriptores & $\mathrm{CM}$ & EA & $\mathrm{EF}$ & LC & LE & MA & L2 & $\%$ \\
\hline \multicolumn{9}{|l|}{ Análisis } \\
\hline $\begin{array}{l}\text { E1a. Capacidad de extraer placer de los aspectos formales, es decir, no solo de } \\
\text { lo que se comunica sino también de la manera como se comunica }\end{array}$ & & 1 & & & & & & 0,79 \\
\hline $\begin{array}{l}\text { E2a. Sensibilidad para reconocer una producción mediática que no se adecue a } \\
\text { unas exigencias mínimas de calidad estética }\end{array}$ & & 1 & & & & & & 0,79 \\
\hline $\begin{array}{l}\text { E3a. Capacidad de relacionar las producciones mediáticas con otras } \\
\text { manifestaciones artísticas, detectando influencias mutuas }\end{array}$ & & 1 & & & & & & 0,79 \\
\hline \multicolumn{9}{|l|}{ Expresión } \\
\hline $\begin{array}{l}\text { E1e. Capacidad de producir mensajes elementales que sean comprensibles y } \\
\text { que contribuyan a incrementar los niveles personales o colectivos de } \\
\text { creatividad, originalidad y sensibilidad }\end{array}$ & 1 & 2 & & & & & & 2,38 \\
\hline $\begin{array}{l}\text { E2e. Capacidad de apropiarse y de transformar producciones artísticas, } \\
\text { potenciando la creatividad, la innovación, la experimentación y la } \\
\text { sensibilidad estética }\end{array}$ & & 2 & & & & & & 1,78 \\
\hline Total & 1 & 7 & 0 & 0 & 0 & 0 & 0 & 8,16 \\
\hline
\end{tabular}

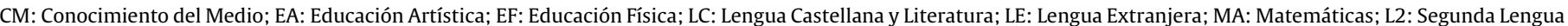
Extranjera.

Fuente: Elaboración propia. 
Asimismo, en todas las áreas se aprecia alguna relación entre los descriptores de la competencia mediática y los criterios de evaluación. Sin embargo, las mayores diferencias en relación con los criterios de evaluación se aprecian en las dimensiones ideología y valores, procesos de interacción y procesos de producción y difusión.

Por su parte, en el conjunto de los criterios de evaluación de todas las áreas los procesos de análisis destacan sobre los de expresión en las dimensiones lenguajes, procesos de interacción e ideologías y valores, mientras que en las dimensiones estética, procesos de producción y difusión y tecnología predominan criterios de evaluación vinculados a los procesos de expresión frente a los de análisis. En cuanto a los procesos de análisis reflejados en los criterios de evaluación, estos solo aparecen en la dimensión ideología y valores.

Las áreas curriculares que tienen mayor presencia en las dimensiones lenguajes y tecnología son CM y LC. en el caso de la dimensión procesos de interacción las áreas con mayor vinculación son CM y EF. Nuevamente, en la dimensión procesos de producción y difusión, los criterios de evaluación de las áreas con mayor predominio de descriptores sobre competencia mediática son CM y LC, a los que se suma en esta ocasión la LE.

En la dimensión ideología y valores, todas las áreas curriculares en cuarto de Educación Primaria contienen descriptores sobre la competencia mediática, especialmente las áreas de LC y CM. Por su parte, los criterios de evaluación del área de EA son los que mayor presencia tienen en la dimensión estética.

Aunque la presencia de la competencia mediática en los criterios de evaluación resulta significativa, es necesario hacerla explícita; es decir, que el término aparezca incluido en el currículo, pues de este modo el docente podrá reconocerla fácilmente cuando establezca su concreción en el aula y así configurará unos indicadores de evaluación específicos para medir el grado de competencia mediática que posea su alumnado, posibilitando iniciar o desarrollar nuevos programas de alfabetización mediática. Asimismo, sería interesante ampliar el estudio a otras etapas educativas con la finalidad de realizar futuras propuestas educativas adaptadas a cada realidad, así como un estudio exhaustivo del nuevo panorama LOMCE (2013) en el que no solo se analizarían los criterios de evaluación, sino también los estándares de aprendizaje evaluables como nuevo elemento curricular que marca la evaluación de las competencias clave.

\section{Financiación}

Proyecto del Ministerio de Economía y Competitividad. I + D La enseñanza obligatoria ante la competencia en comunicación audiovisual en un entorno digital (EDU2010-21395-C03-03).

\section{Conflicto de intereses}

Los autores declaran no tener ningún conflicto de intereses.

\section{Referencias bibliográficas}

Aguaded, J. I., Ferrés i Prats, J., Cruz Díaz, M. R., Pérez Rodríguez, M. A., Sánchez Carrero, J. y Delgado Ponce, Á. (2011). El grado de competencia mediática en la ciudadanía andaluza. Huelva: Grupo Comunicar Ediciones/Grupo de Investigación Ágora, Universidad de Huelva.

Aparici, R., Campuzano, A., Ferrés, J. y García A. (2010). La educación mediática en la escuela 2.0. Recuperado de http://ntic.educacion.es/w3/web_ 20/informes/educacion_mediatica_e20_julio20010.pdf.

Camps, V. (2009). La educación en medios. Más allá de la escuela. Comunicar, 32, $139-145$.

De la Orden, A. (2011). Educación y competencias. Bordón. Revista de Pedagogía, 63(1), 9-12.

Ferrés, J. (2006). La educación en comunicación audiovisual en la era digital. Quaderns del CAC, 25, 5-8.

Ferrés, J. (2007). La competencia en comunicación audiovisual: dimensiones e indicadores. Comunicar, 29, 100-107.

Ferrés, J., Aguaded, J. I. y Aparici, R. (2013). La competencia en comunicación audiovisual en un entorno digital. Investigar la comunicación hoy. Revisión de políticas científicas y aportaciones metodológicas. Simposio Internacional sobre Política Científica en Comunicación. Coord. por Miguel Vicente Mariño, Tecla González y Marta Pacheco, 3, comunicaciones 3, 743-744.

Ferrés, J. y Piscitelli, A. (2012). La competencia mediática: propuesta articulada de dimensiones e indicadores [Media competence. Articulated proposal of dimensions and indicators]. Comunicar, 38, 75-82. (DOI: 10.3916/C38-2012-02-08).

Ferrés, J., García, A., Aguaded, J. I., Fernández, J., Figueras, M., Blanes, M., et al. (2011) Competencia mediática. Investigación sobre el grado de competencia de la ciudadanía en España. Madrid: Ministerio de Educación.

Fox, D. J. (1981). El proceso de investigación en educación. Pamplona: EUNSA.

Gabelas, J. A. y Marta, C. (2011). Grado de competencia en comunicación audiovisual de los aragoneses. Informe. Consejo de Aragón: Zaragoza.

González, N., Sedeño, M. y Gozálvez, V. (2012). Diseño de un focus group para valorar la competencia mediática en escenarios familiares. Icono 14, 10(3), 116-133.

Krippendorf, K. (1997). Metodología de análisis de contenido. Teoría y práctica. Barcelona: Paidós.

Ley Orgánica 2/2006, de 3 de mayo, de Educación. Boletín Oficial del Estado número 106 , de 4 de mayo de 2006.

Ley Orgánica 8/2013, de 9 de diciembre, para la mejora de la calidad educativa. Boletín Oficial del Estado número 295, de 10 de diciembre de 2013.

López, F. (2002). El análisis de contenido como método de investigación. XXI Revista de Educación, 4, 169-179.

Merriënboer, J.; Klink, V. y Hendriks, M. (2002). Competences. Der Haagen: Onderwijsraad.

Moral, M. V. (2006). Efectos psicosociales perversos de la nueva cultura digital en el ámbito educativo. Aula Abierta, 87, 55-70.

Mulder, M. (2004). Education, competence and performance: On training and development in the agri-food complex. Wageningen: Wageningen University. Recuperado el 10/09/2015 de: http://edepot.wur.nl/29019.

OCDE-DeSeCo (2002). Definition and selection of competencies: Theoretical and conceptual foundations. Recuperado el 10/09/2015 de: http://www.portalstat.admin.ch/deseco/index.htm.

Pérez, S. y López, N. (2007). Metodología docente para la enseñanza de los recursos humanos: el uso del cine. Aula Abierta, 35, 63-74.

Real Decreto 1513/06, de 7 de diciembre, por el que se establecen las enseñanzas mínimas de educación primaria, Boletín Oficial del Estado número 293, de 8 de diciembre de 2006.

Recomendación del Parlamento Europeo y del Consejo de 18 de diciembre de 2006 sobre las competencias clave para el aprendizaje permanente (2006/962/CE). Recuperado el 10/09/2015 de: http://www.mcu.es/cine/ docs/Novedades/Recomendacion_Parlamento_Europeo_Consejo_Aprendizaje_ permanente.pdf.

Scheuer, M. (2009). Prólogo. Comunicar, 32, 15-16. XVI

Tiana, A. (2011). Análisis de las competencias básicas como núcleo curricular en la educación obligatoria española. Bordón. Revista de Pedagogía, 63(1), 63-75.

Tucho, F. (2008). La educación en comunicación en la LOE y sus decretos de enseñanzas mínimas. Comunicar, 31, 547-553. 